\title{
Metric Standards Round the Corner
}

The National Bureau of Standards has predictably recommended that the United States should switch over to a metric system of measurement in the course of the next decade. In the report of the US Metric Study, which has occupied the bureau since the passing of the Metric Study Act by Congress in August 1968, the principal theme is that the metric system is for practical purposes unavoidable. "Eventually the United States will join the rest of the world in the use of the metric system as the predominant common language of measurement." But even the adoption of externally designed units of measurement may become a patriotic challenge. "Americans working cooperatively can resolve this question once and for all."

The report of the Metric Study has the inelegant title $\boldsymbol{A}$ Metric America: $\boldsymbol{A}$ Decision whose Time has Come (US Government Printing Office, \$2.50). The supporting evidence presented at the hearings of the study group has been published separately in twelve volumes. Responsibility for the study, originally placed with the Department of Commerce by Congress, has been delegated to the National Bureau of Standards but the Secretary of Commerce has also received advice from a large representative committee. Most of the evidence on which the report is based was collected during the summer of 1970 at public meetings which lasted altogether twenty days.

It remains to be seen what Congress will make of the report on metrication and of the argument that metrication is historically necessary. Congress failed to respond to Jefferson's commendation of the metric system as long ago as 1790 , even before the definition of the metre. Since then, Congress has built up a long record of flirtation with bits and pieces of the metric system, especially at the turn of the century. Most recently, the United States seems to have been prodded into action partly by the National Bureau of Standards itself and partly by the spectacular example of countries such as Britain which have astonished not merely the tourists but themselves in their conversion to the metric cause.

The report of the study group says that the deliberate encouragement of the tendency towards metric could quite quickly create a situation in which the metric system was as widely used as the conventional system in the United States. Schools, it says, should emphasize metric measurements. Industries could be persuaded to conversion before they were forced by cir- cumstances to measure metrically, and public authorities responsible for traffic signs and the like should seize their opportunities to make a captive audience think in kilometres.

In the same spirit of gradualism, and with some regrettable signs of falling for the confusion between units of measurement and standardization of sizes, the committee seeks to comfort anxious Americans by pointing out that it will never be necessary to change the size of an American football field or to alter the gauge of the great railroads (which may in any case be out of business before metric ways are adopted in the United States).

But what will the United States gain from such a development? The study group points out that agreements such as that between the United Kingdom, Germany and France on metric electronics arts, themselves the prototypes of more ambitious agreements yet to be negotiated, could exclude many American products from important markets. The study group has even calculated that American exports likely to be at risk in this sense in 1969 accounted for $\$ 14,000$ million and that an American failure to move towards the metric system will mean that something like $\$ 600$ million worth of exports will be unsold in 1975 .

The Metric Study report points out that the compatibility of United States standards with those of other countries, particularly in Europe, may be particularly important at a time when the United States share of world trade is diminishing steadily-it fell by more than ten per cent during the sixties - and when arrangements such as the European Economic Community will provide further deterrents to American exports. Multi-national corporations are yet another source of pressure towards metrication.

The study group's enquiries among industrial companies seem fully to support its conclusions. In a sample of 4,000 companies chosen to represent American industry as a whole, those for the metric system represent a majority of the labour force, with larger companies more anxious to switch over. As a whole, 70 per cent of the labour force seems to be employed by manufacturers anxious to make the change. Among the general public, the study group's chief discovery seems to be that ignorance is the most common condition-only 40 per cent of the respondents to a social survey were able to name a single metric unit. In industry and among the public as a whole, however, it seems to be accepted that if there is to be a change, it should be planned as a coordinated operation and spread over the next ten years.

With this starting point, the study group urges that there should be a coordinating organization to superintend the changeover. The study group has also singled out two points at which an early start could be made on adaptation to the future-closer participation in the making of international standards and the incorporation of metric measurements into school curricula. In the long run, there will have to be special studies of particular problems such as that already being undertaken by the Industrial Fasteners Institute on the definition of metric thread sizes. Eventually, there will also have to be some decisions about the extent to which collaboration between manufacturers on the development of metric standards can be freed from the threat of anti-trust prosecution. The study group has also committed itself to a complicated cost-benefit analysis of the transition to metric. It assumes, conservatively perhaps, that the benefit of an extra $\$ 600$ million a year on the balance of trade is more than $\$ 1,000$ million for the economy as a whole. Moreover, the study group points out that there would be a number of important economies arising from the way in which the transition to a metric system would provide opportunities for simplifying present practice and, for example, for reducing the numbers of standard items of equipment such as screw thread sizes. The cost of the transition, for manufacturing industry, is estimated to be between $\$ 6,000$ million and $\$ 40,000$ million spread over ten years. In general, therefore, the committee suggests that the costs are unlikely to be much greater than the benefits.

Whether the report now published will finally tip the scales in the United States in favour of conversion to metric may be an open question, but there is no doubt that the report will do a good deal for the moral of the Metrication Board in the United Kingdom, recently much cast down by the apparent indifference of the Conservative Government. Indeed, the working group declares that the British metrication programme should be regarded as a pilot for the conversion in the United States. Lord Ritchie-Calder, chairman of the Metrication Board, will no doubt be reminded once more that prophets are not highly regarded in their own countries. 